\title{
Using an Integrated Framework for Conceptual Modeling
}

\author{
Lindita Nebiu Hyseni, PhD \\ Faculty of Computer Sciences \\ Kadri Zeka University \\ Gjilan, Kosovo
}

\author{
Zamir Dika, PhD \\ Faculty of Contemporary Sciences and Technologies \\ South East European University \\ Tetovo, Macedonia
}

\begin{abstract}
The Integrated Framework for Conceptual Modeling (IFCMod) is created to contribute to the quality of the information system through the integration of the functional and non-functional requirements. This paper attempts to explore the outcomes of the IFCMod usage through the Mixed Method Case Studies at the Higher Education Institution and the Central Bank. The case study at the South East European University (SEEU) was the analysis and design of the improvement of the eSchedule system, while the case study at the Central Bank of the Republic of Kosovo (CBK) was the analysis and design of the Data Collection System for Enterprise Surveys (DCSES). Based on the institutional perspective of the community participation during the semi-structure interviews, at the end of the Joint Approval Requirements (JAR) meetings, in both cases, the outcomes showed that IFCMod usage increases the quality of the information system by increasing quality in the system requirements.
\end{abstract}

Keywords-Integrated framework for conceptual modeling (IFCMod); joint approval requirements (JAR); system requirements; information system; mixed method case studies

\section{INTRODUCTION}

The conceptual modeling $(\mathrm{CM})$ has a long tradition in the information system (IS) research [1]. The CM supports understanding and communication of the system requirements during the IS development [2], [28]. It has a significant role in the success of the IS [3-5] because of the understandability of the requirements by all project participants. Therefore, was created the Integrated Framework for Conceptual Modeling (IFCMod) in order to integrate the functional (FRs) and nonfunctional requirements (NFRs) [6]. After its creation, the research questions followed; was it possible to increase quality in the Information System by increasing quality in the System Requirements via IFCMod usage? Based on this research question, there were explored the outcomes of IFCMod usage during the system analysis and design stage through the following Mixed Methods Case Studies: analysis and designing of the improvement of the e-Schedule at the South East European University (SEEU), and analysis and design of the Data Collection System for Enterprise Surveys (DCSES) at the Central Bank of the Republic of Kosovo (CBK).

The most convenient research method to explore the outcomes of this complexity study was the Mixed Methods Case Study [16] because it allows collecting, analyzing, and integrating the qualitative and quantitative aspects of the study to answer the research question through interpretation of the significant results.

The aim of this paper was the interpretation of the significant results received from the institutional perspectives where the IFCMod was used to gather and to document requirements by the contractor, understand, review and approve the requirements by client in meeting with the contractor using the Joint Approval Requirements (JAR) method.

This paper was organized as follows: in the section 2 is a state of the art; in the section 3 are presented the materials and methods; in the section 4 are presented the outcomes from the IFCMod usage at the South East European University (SEEU) and at the Central Bank of the Republic of Kosovo (CBK); in the section 5 is discussion; in the section 6 is the research limitations; in the section 7 is the conclusion and future work; at the end, in the last section are presented the references used in this paper.

\section{RELEATED WORK}

Through the conducted research was identified the small number of scholars who had been working for the requirements integration, even if they have started to reinitiate this issue in the year 2016, they did not present the final solution per integration of the functional and non-functional requirements in one conceptual model. A solution that would help all project participants to understand the system requirements during the system analysis and design stage [2], [7].

Most of the scholars have been divided the nature of the system requirements into the functional (FRs) and nonfunctional requirements (NFRs) by representing them separately into the CM and requirements documents [8-12]. Cysneiros et al. (2001) [13], have proposed a framework for integrating the non-functional requirements into conceptual models, but their strategy was not transferable to real world situations because of missing adequate tools and methods for system development. Also, Cysneiros and Leite (2004) [14] has given another solution to the integration of the FRs and NFRs but the strategy that they used had several problems in the functional models and had no significantly impact on the overall development process. Moreover, the authors Eckhardt, Vogelsang, and Fernández (2016) [15] hint the possibility of the integration of the functional requirements (FRs) and nonfunctional requirements (NFRs) by handling most of the NFRs similar to the FRs. This hint was the main motivation for 
creation of the Integrated Framework for Conceptual Modeling (IFCMod) which consisted guides to deal with the requirements gathering, the creation of the functional and nonfunctional requirements document and the conceptual model of the information system. The IFCMod consist also the Joint Approval Requirements (JAR) methods which allow clients reviewing and approving of the requirements document and conceptual model which are created based on guides.
Based on conducted research, there were two techniques per requirements definition, documentation, validation and approval, such as Joint Requirements Planning (JRP) [26] and Joint Application Development (JAD) [27]. In comparison with the JAR method. These techniques differ in a few aspects that are presented in the following Table I.

TABLE I. COMPARASION OF THE JAR METHOD AND TECHNIQUES: JRP AND JAD

Aspects of the JAR method and techniques

\begin{tabular}{|c|c|c|c|c|}
\hline $\begin{array}{l}\text { Joint Approval } \\
\text { Requirements (JAR) }\end{array}$ & $\begin{array}{l}\text { Functional and Non-Functional } \\
\text { Requirements Document was } \\
\text { created by contractor before } \\
\text { meetings with the client. It is } \\
\text { created based on gathering } \\
\text { requirements from relevant } \\
\text { materials of the institution. }\end{array}$ & $\begin{array}{l}\text { Conceptual Model of Functional and } \\
\text { Non-Functional Requirements was } \\
\text { designed by contractor before meetings } \\
\text { with the client. It was created based on } \\
\text { gathering requirements from relevant } \\
\text { materials of the institution. }\end{array}$ & $\begin{array}{l}\text { Review \& Approve of the } \\
\text { prepared Requirements } \\
\text { Document by client } \\
\text { during the meetings with } \\
\text { the contractor }\end{array}$ & $\begin{array}{l}\text { Review \& Approve of } \\
\text { the prepared Conceptual } \\
\text { Model by client during } \\
\text { the meetings with the } \\
\text { contractor }\end{array}$ \\
\hline $\begin{array}{l}\text { Joint Requirements } \\
\text { Planning (JRP) }\end{array}$ & $\begin{array}{l}\text { The formal written document was } \\
\text { published immediately following } \\
\text { the JRP session. } \\
\text { The content of the formal } \\
\text { document is depended on the } \\
\text { objective of the JRP session. }\end{array}$ & $\begin{array}{l}\text { It is created Prototypes by contractor } \\
\text { during the JRP session only per } \\
\text { Functional Requirements if have }\end{array}$ & $\begin{array}{l}\text { Confirm Requirements by } \\
\text { client during the JRP } \\
\text { session }\end{array}$ & $\begin{array}{l}\text { Approve Prototypes by } \\
\text { client during the JRP } \\
\text { session only per } \\
\text { Functional Requirements } \\
\text { in case they had so. }\end{array}$ \\
\hline $\begin{array}{l}\text { Joint Application } \\
\text { Development (JAD) }\end{array}$ & $\begin{array}{l}\text { It was required to develop a set of } \\
\text { questions before starting the JAD } \\
\text { sessions. } \\
\text { The post-session report was } \\
\text { created 2-3 weeks after JAD } \\
\text { session }\end{array}$ & Not applied & $\begin{array}{l}\text { All issues were discussed } \\
\text { by client and contractor in } \\
\text { the JAD Session and the } \\
\text { needed information was } \\
\text { collected }\end{array}$ & Not applied \\
\hline
\end{tabular}

The aspects of the techniques presented in the Table I, were also a motivation to add the Joint Approval Requirements (JAR) method as a component of the Integrated Framework for Conceptual Modeling which had the missing aspects in the JRP and JAD technique. Moreover, these missing aspects in the techniques have pushed the Higher Education Institution and the Central Bank using the JAR method and guides of the Integrated Framework for Conceptual Modeling during the system analysis and design. Before the JAR method, the Higher Education Institution has used the JRP technique, while the Central Bank has used the JAD technique during system analysis and design.

\section{MATERIALS AND METHODS}

In 2017, at the Higher Education Institution and at the Central Bank [16] was applied the Mixed Methods Case Study to explore the outcomes of the Integrated Framework for Conceptual Modeling (IFCMod) usage. While, the Sequential Exploratory Design (QUAL $\rightarrow$ quan) [17-19], [28] was used for exploration because it gave priority to the qualitative aspects of the study. This design initiated the qualitative data collection and analysis phase than the qualitative components followed by the quantitative data collection and analysis phase with the aim of findings the generalization increasement.

The qualitative data were collected from semi-structured interviews held at the end of the JAR [19] meetings at the South East European University (SEEU) and at the Central
Bank of the Republic of Kosovo (CBK). In this research study, the community participation from the SEEU were the Top Management, Managers, Employees, and Students, while from the CBK were the Top Management, Mangers, Employees and the representative of enterprises with foreign owned capital in Kosovo who reports to CBK. Moreover, in both institution these Joint Approval Requirements meetings were organized to review and approve the functional and non-functional requirements document (FRs \& NFRs DOC) and the integrated conceptual model (ICM) which was created using the guides of the IFCMod.

The criteria for inclusion the above-mentioned community of the SEEU was that they should have been invited in the Quarantine of the year 2014 which was held for analyzing and designing of the e-Schedule system by using JRP technique or they should have used or developed that e-Schedule system in order to be invited in the JAR meetings of the year of 2017 for improvement of the e-Schedule system [19]. From this community who participate in the JAR meetings in the year 2017 was collected 15 qualitative semi-structured interviews. Of the 15 participants interviewed, 2 were from Top Management, 2 from IT Department, 6 from Faculties, 2 from the Human Resources Department, 1 from Student Services and 2 from Academic Planning.

Also, the CBK community was included in the research study based on criteria which they should have been involved in the process of data collection from the enterprises survey 
and should have experience in CBK (priority was the experience in JAD techniques), while the criteria for inclusion the representative of enterprises with foreign owned capital in Kosovo was that they should have been involved in the process of data reporting to CBK. From this community who participate in the JAR meetings in the year 2017 was collected 25 qualitative semi-structured interviews. Of the 25 participants interviewed, 2 were from Top Management, one of them from $\mathrm{CBK}$ and one from Enterprises; 7 from Manager positions, one of them from $\mathrm{CBK}$ and six from Enterprises; 16 from Employees, three of them from IT Departments.

In both institutions, the interview lasted per half hour and interview questions were focused on the effect of the IFCMod in the quality of the system requirements and the information system. During interviews, the ethical principle 'Doing no harm' was respected, where were developed and maintained the relationships of trust with participants in the Mixed Method Case Study. The transcribed interviews were transformed into categorical data which were classified into two binary classifications because it will unequivocally highlight the effect of the IFCMod based on participants` responses [20]. The categorical data were analyzed using SPSS in order to discover if there was a relationship between categorical variables. In this case, were used the Fisher's Exact test because of small sample size [22-25]. The results of this test are presented in the section 4. During this research study was also treated the dilemma about the small number of sampling. According to the authors Marshall, B., Cardon, P., Poddar, A., \& Fontenot, R. (2013) data saturation had occurred by 12 interviews while, theoretical saturation generally occurs between 10 and 30 interviews. Based on the authors, the single case study should generally contain 15 to 30 interviews [23]. Whilst, the authors Malterud, K., Siersma, V. D., \& Guassora, A. D. (2016) highlighted that the information power indicates the lower number of participants in the interviews. It depends on the aim of the study, sample specificity, use of established theory, quality of dialogue, and analysis strategy [24]. Furthermore, the authors Ghazi, A. N., Petersen, K., Reddy, S. S. V. R., \& Nekkanti, H. (2017) based on literature review highlighted that this is a problem in the field of software engineering [25]. In the following sections, the outcomes of the Mixed Method Case Studies should be presented.

\section{RESULTS OF USING IFCMOD}

The research question; was it possible to increase quality in the Information System by increasing quality in the System Requirements via IFCMod usage? was addressed through the Mixed Methods Case Study at the South East European University (SEEU) and at the Central Bank of the Republic of Kosovo. In the following subsections are presented the interpretations of the significant results received from the above-mentioned institutions perspectives where the IFCMod is used [16], [18], [28].

\section{A. Improvement of the E-Schedule System}

The outcomes of using Integrated Framework for Conceptual Modeling (IFCMod) at the South East European University (SEEU) during the analysis and design of the improvement of the e-Schedule system were explored through Mixed Methods Case Study to gain a better understanding of IFCMod effect based on the perspectives of the community participation during the semi-structure interviews, at the end of the JAR meetings [21].

Considering the focus of the semi-structure interview, which was the effect of the IFCMod in the quality of the system requirements (SRs) and the information system (IS), variable about this effect was analyzed for its association with the other variables, this is shown in the Table II.

TABLE II. RESULTS OF USING IFCMOD AT THE SEEU

\section{Fisher's Exact Test}

\begin{tabular}{|l|l|l|}
\hline Variable association & $\begin{array}{l}\text { The effect of the IFCMod in the } \\
\text { quality of the System Requirements } \\
(\text { SRs) and the Information System } \\
(I S)\end{array}$ & $\begin{array}{l}\text { The understandability of the requirement document } \\
\text { from all participants in the JAR meetings was used as a } \\
\text { control variable to assess the relationship between } \\
\text { variables }\end{array}$ \\
\hline $\begin{array}{l}\text { 1) Understandability of the Integrated Conceptual Model } \\
\text { (ICM) }\end{array}$ & P value: .011 & P value: .011 \\
\hline $\begin{array}{l}\text { 2) FRs \& NFRs DOC and ICM help the system developer } \\
\text { during the system development }\end{array}$ & P value: .011 & P value: .011 \\
\hline $\begin{array}{l}\text { 3) Facilitation of the communication through Functional } \\
\text { Requirements and Non-Functional Requirements } \\
\text { Document (FRs \& NFRs DOC) and Integrated Conceptual } \\
\text { Model (ICM) }\end{array}$ & P value: .033 & P value: .0033 \\
\hline $\begin{array}{l}\text { 4) Review and Approve of FRs \& NFRs DOC and ICM } \\
\text { from all participants in the JAR meetings }\end{array}$ & P value: .033 & P value: .033 \\
\hline
\end{tabular}


Based on the outcomes from the perspective of the SEE University, the increasing of the quality in system requirements and information system depended on variables listed on the Table II. The interpretation of the significant results received from the institutional perspectives per variables are presented in the following.

\section{1) Understandability of the Integrated Conceptual Model} (ICM)

Based on the results presented in the Table II, this study found that the effect of the IFCMod in the quality of the System Requirements (SRs) and Information System (IS) was significantly and statistically associated with the understandability of the Integrated Conceptual Model. This was shown through the result of $\mathrm{p}$ value which is $\mathrm{p}=0.011$. Also, the understandability of the requirement document from all participants in the JAR meetings was used as a control variable to assess the relationship between above variables. Based on the Fisher's Exact test, this variable controlled the relationship of the other variables based on the statistically significant results $\mathrm{p}=0.011$.

2) Facilitation of the communication through Functional Requirements and Non-Functional Requirements Document (FRs \& NFRs DOC) and Integrated Conceptual Model (ICM)

In the Table II are presented the results of this study which found that the effect of the IFCMod in the quality of the SRs and IS, was significantly and statistically associated with facilitation of the communication through Functional Requirements and Non-Functional Requirements Document (FRs \& NFRs DOC) and Integrated Conceptual Model (ICM). This was shown through the result of $\mathrm{p}$ value which is $\mathrm{p}=0.033$. Also, the understandability of the requirement document from all participants in the JAR meetings was used as a control variable to assess the relationship between above variables. Based on the Fisher's Exact test, this variable controlled the relationship of the other variables based on the statistically significant results $\mathrm{p}=0.033$.

3) FRs \& NFRs DOC and ICM help the system developer during the system development

The results of this study presented in the Table II found that the effect of the IFCMod in the quality of the SRs and IS, was significantly and statistically associated with how much FRs \& NFRs DOC and ICM help the system developer during the system development. This was shown through the result of $p$ value which is $\mathrm{p}=0.011$. Also, the understandability of the requirement document from all participants in the JAR meetings were used as a control variable to assess the relationship between above variables. Based on the Fisher's Exact test, this variable controlled the relationship of the other variables based on the statistically significant results $\mathrm{p}=0.011$.

4) Review and Approve of FRs \& NFRs DOC and ICM from all participants in the JAR meetings

As it is shown in the Table II, this study found that the effect of the IFCMod in the quality of the SRs and IS, was significantly and statistically associated with Review and Approve of FRs \& NFRs DOC and ICM from all participants in the JAR meetings. This was shown through the result of $p$ value which is $\mathrm{p}=0.033$. Also, the understandability of the requirement document from all participants in the JAR meetings was used as a control variable to assess the relationship between above variables. Based on the Fisher's Exact test, this variable controlled the relationship of the other variables based on the statistically significant results $\mathrm{p}=0.033$.

\section{B. Analysis and Design of the Data Collection System for Enterprise Surveys (DCSES)}

Throughout the research study at the Central Bank of the Republic of Kosovo (CBK), was used the Integrated Framework for Conceptual Modeling (IFCMod) to analyze and design the Data Collection System for Enterprise Surveys (DCSES). The intention of this study was to explore the outcomes of IFCMod usage through Mixed Methods Case Study in order to gain a better understanding of its effect based on the perspectives of the community participation during the semi-structure interviews at the end of the JAR meetings [21].

Considering the focus of the semi-structure interview, which was the effect of the IFCMod in the quality of the system requirements (SRs) and the information system (IS), variable about this effect was analyzed for its association with the other variables, this is shown in the Table III.

TABLE III. RESULTS OF USING IFCMOD AT THE CBK

Fisher's Exact Test

Variable association

Understandability of the Integrated Conceptual Model (ICM)

FRs \& NFRs DOC and ICM help the system developer during the system development

Review and Approve of FRs \& NFRs DOC and ICM from all participants in the JAR meetings
The effect of the IFCMod in the quality of the System Requirements (SRs) and the Information System (IS)

P value: .022

P value: .018

P value: .018
P value: .010

The understandability of the requirement document from all participants in the JAR meetings was used as a control variable to assess the relationship between variables

P value: .022

P value: .022 
In Table III, are listed the variables in which are depended on the increase of the quality in system requirements and information system based on the outcomes from the perspective of the CBK. The interpretation of the significant results received from the institutional perspectives per variables is presented in the following.

\section{1) Understandability of the Integrated Conceptual Model} (ICM)

Based on the results presented in the Table III, this study found that the effect of the IFCMod in the quality of the SRs and IS was significantly and statistically associated with the understandability of the Integrated Conceptual Model. This was shown through the result of $p$ value which is $p=0.022$. Also, the understandability of the requirement document from all participants in the JAR meetings was used as a control variable to assess the relationship between above variables. Based on the Fisher's Exact test, this variable controlled the relationship of the other variables based on the statistically significant results $\mathrm{p}=0.022$.

2) FRs \& NFRs DOC and ICM help the system developer during the system development

The results of this study presented in the Table III found that the effect of the IFCMod in the quality of the SRs and IS, was significantly and statistically associated with the amount of FRs \& NFRs DOC and ICM helping the system developer during the system development. This was shown through the result of $\mathrm{p}$ value which is $\mathrm{p}=0.018$ which meant there was a statistically significant association between effect of the IFCMod in the quality of the SRs and IS, and the amount of FRs \& NFRs DOC and ICM helping the system developer during the development of the DCSES system. Also, the understandability of the requirement document from all participants in the JAR meetings was used as a control variable to assess the relationship between above variables. Based on the Fisher's Exact test, this variable controlled the relationship of the other variables based on the statistically significant results $\mathrm{p}=0.022$.

3) Review and Approve of FRs \& NFRs DOC and ICM from all participants in the JAR meetings

Based on the results in the Table III, this study found that the effect of the IFCMod in the quality of the SRs and IS was significantly and statistically associated with Review and Approve of FRs \& NFRs DOC and ICM from all participants in the JAR meetings. This was shown through the result of $p$ value which is $\mathrm{p}=0.018$. Also, the understandability of the requirement document from all participants in the JAR meetings was used as a control variable to assess the relationship between above variables. Based on the Fisher's Exact test, this variable controlled the relationship of the other variables based on the statistically significant results $\mathrm{p}=0.010$.

\section{DISCUSSION}

The IFCMod is used through Mixed Method Case Study at the Higher Education Institution and at the Central Bank in order to gain better understanding of its effect in the quality of the system requirements (SRs) and the information system (IS) considering the perspectives of the community participation during the semi-structure interviews at the end of the JAR meetings in these institutions. Unexpected finding is the weakness of the IFCMod which is that only participants with the experience in system analysis and design stage agreed that the IFCMod facilitated the communication during system development. While, the strength of the IFCMod based on finding is the understandability of the functional and nonfunctional requirement document and conceptual model by client and contractor side, and the application of the JAR Method to approve and review requirement document and the conceptual model by the client side in the JAR meetings with the contractor.

\section{RESEARCH LIMITATIONS}

The research limitation was the lack of similar work in the integration of the functional and non-functional requirements. Moreover, the sample size from both institutions was dictated from the nature being studied [23-24], [29-31]. The participants in the study are selected based on the criteria listed in Section 3, in order to provide the best data [32] therefore the sample size is acceptable [24].

\section{CONCLUSIONS AND FUTURE WORK}

The Integrated Framework for Conceptual Modeling (IFCMod) was created and used at the South East European University (SEEU) during the improvements of the e-Schedule system. Also, the IFCMod was used at the Central Bank of the Republic of Kosovo during the analysis and design of the Data Collection System for Enterprise Surveys (DCSES). Both usages were done through Mixed Methods Case Studies because of the complexity of the research study [16]. Based on the outcomes from the institutional perspectives of the SEEU and CBK, understandability of the Functional and NonFunctional Requirements Document (FRs \& NFRs DOC) and the Integrated Conceptual Model (ICM) from all participants in the Joint Approval Requirements meetings increased the quality in the System Requirements (SRs). Also, the review and approve of the FRs \& NFRs DOC and the ICM during the JAR meetings of the client and the contractor increase the quality of the SRs. Both institutions are agreed that the IFCMod help system developer during the system development, while only SEEU is agreed that it facilitate the communication between the contractor and the client during the system development. The IFCMod is ready to be used in different industries in order to explore the outcomes of its usage and compare them with the outcomes of this research paper.

The future work would be a creation of the new component of the IFCMod, the Price Model (PM). The PM shall present the way of calculation of total cost per information system development based on Functional and Non-Functional Requirements Document (FRs \& NFRs DOC) and the Integrated Conceptual Model (ICM).

\section{REFERENCES}

[1] Borgida, Alexander. "Conceptual modeling of information systems." In On Knowledge Base Management Systems, pp. 461-469. Springer, New York, NY, 1986. 
[2] Hyseni, Lindita Nebiu, and Zamir Dika. "Integrated Approach to Conceptual Modeling." International Journal of Advanced Computer Science and Applications 7, no. 12 (2016): 213-219.

[3] Bera, Palash, Anna Krasnoperova, and Yair Wand. "Using ontology languages for conceptual modeling." Journal of Database Management (JDM) 21, no. 1 (2010): 1-28.

[4] Braga, Bernardo FB, João Paulo Andrade Almeida, Giancarlo Guizzardi, and Alessander B. Benevides. "Transforming OntoUML into Alloy: towards conceptual model validation using a lightweight formal method." Innovations in Systems and Software Engineering 6, no. 1-2 (2010): 55-63.

[5] Mehmood, Kashif, Samira Si-Said Cherfi, and Isabelle Comyn-Wattiau. "CM-Quality: a pattern-based method and tool for conceptual modeling evaluation and improvement." In East European Conference on Advances in Databases and Information Systems, pp. 406-420. Springer, Berlin, Heidelberg, 2010.

[6] Hyseni, Lindita Nebiu, and Zamir Dika. "An integrated framework of conceptual modeling for performance improvement of the information systems." In Innovative Computing Technology (INTECH), 2017 Seventh International Conference on, pp. 174-180. IEEE, 2017.

[7] Robinson, Stewart. "Tutorial: Choosing what to model—Conceptual modeling for simulation." In Simulation Conference (WSC), Proceedings of the 2012 Winter, pp. 1-12. IEEE, 2012.

[8] Sommerville, Ian, and Pete Sawyer. Requirements engineering: a good practice guide. John Wiley \& Sons, Inc., 1997.

[9] Gorschek, Tony, and Claes Wohlin. "Requirements abstraction model." Requirements Engineering 11, no. 1 (2006): 79-101.

[10] Fatwanto, Agung, and Clive Boughton. "Analysis, specification and modeling of non-functional requirements for translative model-driven development." In Computational Intelligence and Security, 2008. CIS'08. International Conference on, vol. 2, pp. 405-410. IEEE, 2008.

[11] Fatwanto, Agung, and Clive Boughton. "Analysis, Specification and Modeling of Functional Requirements for Translative Model-Driven Development." In Knowledge Acquisition and Modeling, 2008. KAM'08. International Symposium on, pp. 859-863. IEEE, 2008.

[12] Sommerville, I., \& Sawyer, P. "Requirements engineering (10th Edition)", Pearson, 2015.

[13] Cysneiros, Luiz Marcio, Julio Cesar Sampaio do Prado Leite, and Jaime de Melo Sabat Neto. "A framework for integrating non-functional requirements into conceptual models." Requirements Engineering 6, no. 2 (2001): 97-115.

[14] Cysneiros, Luiz Marcio, and Julio Cesar Sampaio do Prado Leite. "Nonfunctional requirements: From elicitation to conceptual models." IEEE transactions on Software engineering 30, no. 5 (2004): 328-350.

[15] Eckhardt, Jonas, Andreas Vogelsang, and Daniel Méndez Fernández. "Are" Non-functional" Requirements really Non-functional? An Investigation of Non-functional Requirements in Practice." In Software Engineering (ICSE), 2016 IEEE/ACM 38th International Conference on, pp. 832-842. IEEE, 2016.
[16] Morse, Janice M. Mixed method design: Principles and procedures. Routledge, 2016.

[17] Peng, Guo Chao, J. M. B. Nunes, and Fenio Annansingh. "Investigating information systems with mixed-methods research." In Proceedings of the IADIS International Workshop on Information Systems Research Trends, Approaches and Methodologies. Sheffield, 2011.

[18] Cameron, Roslyn. "A sequential mixed model research design: Design, analytical and display issues." International Journal of Multiple Research Approaches 3, no. 2 (2009): 140-152.

[19] Hyseni, Lindita Nebiu, and Zamir Dika. "Method for System Requirements Approval." INTERNATIONAL JOURNAL OF ADVANCED COMPUTER SCIENCE AND APPLICATIONS 8, no. 7 (2017): 331-336.

[20] Hashi, Iraj, and Besnik A. Krasniqi. "Entrepreneurship and SME growth: evidence from advanced and laggard transition economies." International Journal of Entrepreneurial Behavior \& Research 17, no. 5 (2011): 456-487.

[21] Myers, Michael D., and Michael Newman. "The qualitative interview in IS research: Examining the craft." Information and organization 17, no. 1 (2007): 2-26.

[22] Freeman, Jenny V., and Steven A. Julious. "The analysis of categorical data." Scope 16, no. 1 (2007): 18-21.

[23] Marshall, Bryan, Peter Cardon, Amit Poddar, and Renee Fontenot. "Does sample size matter in qualitative research?: A review of qualitative interviews in IS research." Journal of Computer Information Systems 54, no. 1 (2013): 11-22.

[24] Malterud, Kirsti, Volkert Dirk Siersma, and Ann Dorrit Guassora. "Sample size in qualitative interview studies: guided by information power." Qualitative health research 26, no. 13 (2016): 1753-1760.

[25] Ghazi, Ahmad Nauman, Kai Petersen, Sri Sai Vijay Raj Reddy, and Harini Nekkanti. "Survey research in software engineering: problems and strategies." arXiv preprint arXiv: 1704.01090 (2017).

[26] Bentley, Lonnie D., and Jeffrey L. Whitten. Systems analysis and design methods. Irwin/McGraw Hill, pp. 229-235. 2007.

[27] Dennis, Alan, Barbara Haley Wixom, and Roberta M. Roth. "Systems analysis and design." John wiley \& sons, pp. 119-143. 2012. AramoImmonen, Heli. "Mixed methods research design." In World Summit on Knowledge Society, pp. 32-43. Springer, Berlin, Heidelberg, 2011.

[28] Lakhoua, M. N., and F. Khanchel. "Overview of the methods of modeling and analyzing for the medical framework." Scientific Research and Essays 6, no. 19 (2011): 3942-3948.

[29] Morse, Janice M. "Determining sample size." (2000): 3-5.

[30] Sobal, Jeffery. "Sample extensiveness in qualitative nutrition education research." Journal of Nutrition Education 33, no. 4 (2001): 184-192.

[31] Thomson, S. Bruce. "Sample size and grounded theory." (2010).

[32] Strauss, A., and J. Corbin. "Basics of Qualitative Research. Sage Publications." Thousand Oaks, CA (1998). 